\title{
Colourings in Bipartite Graphs
}

\author{
Y.B.Venkatakrishnan \\ School of Humanities and \\ Sciences \\ SASTRA University \\ Thanjavur 613 401. India
}

\author{
V.Swaminathan \\ Co-ordinator(Retd) \\ Ramunajan Research Center \\ S.N.College \\ Madurai. India
}

\begin{abstract}
The concept of X-chromatic partition and hyper independent chromatic partition of bipartite graphs were introduced by Stephen Hedetniemi and Renu Laskar. We find the bounds for $\mathrm{X}$-chromatic number and hyper independent chromatic number of a bipartite graph. The existence of bipartite graph with $\chi_{\mathrm{h}}(\mathrm{G})=\mathrm{a}$ and $\gamma_{\mathrm{Y}}(\mathrm{G})=\mathrm{b}-1, \chi_{\mathrm{h}}(\mathrm{G})=\mathrm{a}$ and $\chi_{\mathrm{X}}(\mathrm{G})=\mathrm{b}$ where $\mathrm{a} \leq \mathrm{b}$ are proved. We also prove the existence of bipartite graphs for any three positive integers $a, b, c$ such that $c \geq 2(b-a)+1$, there exists a graph $\mathrm{G}$ such that $\chi_{X}(\mathrm{G})=\mathrm{a}, \chi_{\mathrm{X}} \mathrm{d}(\mathrm{G})=\mathrm{b}$ and $|\mathrm{Y}|=\mathrm{c}$. The bipartite theory of Dominator colouring is introduced.
\end{abstract}

\section{Keywords}

X.Chromatic number, hyper independent chromatic number, Xdominator $\mathrm{X}$-colouring of a graph.

\section{INTRODUCTION}

Bipartite theory of graph introduced by Hedetniemi [4,5] and Renu Laskar states that given any graph problem, say $\mathrm{P}$, there is corresponding problem, say Q, on bipartite graph whose solution gives a solution for the problem $\mathrm{P}$. The concept of X-chromatic and hyper independent chromatic partition introduced in [4,5] are studied. Varities of domination is discussed in the two books of T.W.Haynes[2,3]. The concept of X-dominator X-colouring which is bipartite version of dominator colouring [1] is introduced. Unless otherwise stated, by a graph we mean bipartite graph $\mathrm{G}=(\mathrm{X}, \mathrm{Y}, \mathrm{E})$ with $|\mathrm{X}|=\mathrm{p}$ without isolates.

\section{X-COLOURING IN GRAPHS}

In this section, we give the definition of X-colouring of a bipartite graph $\mathrm{G}$ as given in [4] and find its bounds.

Definition 2.1: [4] Let $G$ be a graph. Two vertices $u, v \in X$ are $\mathrm{X}$-adjacent if they are adjacent to a common vertex in $\mathrm{Y}$. Let $d_{Y}(x)$ denote the number of vertices $X$-adjacent to $x$.

Definition 2.2: [4] Two vertices $u, v \in X$ are $X$-independent if there does not exist a vertex $y \in Y$ adjacent to both $u$ and $v$. A subset $\mathrm{S}$ of $\mathrm{X}$ is $\mathrm{X}$-independent if every pair of vertices $\mathrm{u}$ and $\mathrm{v}$ in $\mathrm{S}$ of $\mathrm{X}$ is $\mathrm{X}$-independent. The maximum cardinality of a Xindependent set is called $\mathrm{X}$-independence number of $\mathrm{G}$ and is denoted by $\beta_{\mathrm{X}}(\mathrm{G})$.
Definition 2.3: [4] A $X$-colouring of a bipartite graph $G$ is a partition $\left\{\mathrm{X}_{1}, \mathrm{X}_{2}, \ldots, \mathrm{X}_{\mathrm{k}}\right\}$ of $\mathrm{X}$ into $\mathrm{X}$-independent sets. The $\mathrm{X}$ chromatic number $\chi_{\mathrm{X}}(\mathrm{G})$ of a bipartite graph is the smallest order of an X-colouring of $\mathrm{G}$.

Theorem 2.4: Given positive integers $\mathrm{k}$ and $\mathrm{p}, 2 \leq \mathrm{k} \leq \mathrm{p}$, there exists a graph with $\chi_{X}(G)=k,|X|=p$ and $|Y|=q(q \geq p)$.

Proof: Let $\mathrm{G}$ be a bipartite graph with bipartition $\mathrm{X}$ and $\mathrm{Y}$. The bipartite graph $\mathrm{G}$ is defined as follows: $\mathrm{X}=\left\{\mathrm{u}_{1}, \mathrm{u}_{2}, \ldots, \mathrm{u}_{\mathrm{p}}\right\}, \mathrm{Y}=$ $\left\{\mathrm{y}_{1}, \mathrm{y}_{2}, \ldots, \mathrm{y}_{\mathrm{q}}\right\}, \mathrm{k}$ vertices $\mathrm{u}_{1}, \mathrm{u}_{2}, \ldots, \mathrm{u}_{\mathrm{k}}$ are $\mathrm{X}$-adjacent to each other through same $\mathrm{y}_{1} \in \mathrm{Y}$. Let $\mathrm{u}_{\mathrm{k}+1}$ be $\mathrm{X}$-adjacent to each other through different $\mathrm{y} \in \mathrm{Y}-\left\{\mathrm{y}_{1}\right\}$ say $\mathrm{y}_{2} . \mathrm{u}_{\mathrm{k}+2}$ is $\mathrm{X}$-adjacent to $\mathrm{u}_{2}$ through $\mathrm{y}_{3}$ where $\mathrm{y}_{3} \in \mathrm{Y}-\left\{\mathrm{y}_{1}, \mathrm{y}_{2}\right\}$ and so on. If $\mathrm{p}-\mathrm{k}$ is greater than $\mathrm{k}$ then $\mathrm{u}_{2 \mathrm{k}+1}$ is made $\mathrm{X}$-adjacent to $\mathrm{u}_{1}$ and so on.

Since $k$ vertices in $X$ are $X$-adjacent, $\chi_{X}(G) \geq k$. Let $X_{i}$ be the set with elements $u_{i}$ and $X$-neighbours of $u_{i+1} 1 \leq i \leq k-1$. Let $X_{k}$ be the set with vertices $u_{k}$ and $X$-neighbours of $u_{1}$. Then, $\left\{X_{1}, X_{2}\right.$, $\left.\ldots, X_{k}\right\}$ forms a $X$-chromatic partition. Hence, $\quad \chi_{X}(G) \leq k$. Therefore, $\chi_{X}(G)=k$ with $|X|=p$.

Theorem 2.5: In a bipartite graph $\mathrm{G}, \chi_{\mathrm{X}}(\mathrm{G})=\mathrm{p}$ if and only if $\mathrm{G}$ is a graph with every vertex in $\mathrm{X}$ is (p-1) X-regular.

Proof: If every vertex in $\mathrm{X}$ is (p-1) $\mathrm{X}$-regular then $\left\{\mathrm{x}_{1}\right\}$, $\left.\left\{\mathrm{x}_{2}\right\}, \ldots,\left\{\mathrm{x}_{\mathrm{p}}\right\}\right\}$ is a partition of $\mathrm{X}$ into $\mathrm{X}$-independent sets. Therefore, $\chi_{X}(G)=p$.

Conversely, $\chi_{X}(G)=p$ then $\left\{\left\{x_{1}\right\},\left\{x_{2}\right\}, \ldots,\left\{x_{p}\right\}\right\}$ is a partition of $\mathrm{X}$ into $\mathrm{X}$-independent sets. If there exists a vertex $\mathrm{x}_{\mathrm{i}}$ with $\mathrm{d}_{\mathrm{Y}}\left(\mathrm{x}_{\mathrm{i}}\right)$ $<\mathrm{p}-1$. Let $\mathrm{x}_{\mathrm{k}}$ be the vertex not $\mathrm{X}$-adjacent with $\mathrm{x}_{\mathrm{i}}$. Then, $\left\{\left\{\mathrm{x}_{1}\right\}\right.$, $\left.\left\{\mathrm{x}_{2}\right\}, \ldots,\left\{\mathrm{x}_{\mathrm{i}-1}\right\},\left\{\mathrm{x}_{\mathrm{i}}, \mathrm{x}_{\mathrm{k}}\right\}, \ldots,\left\{\mathrm{x}_{\mathrm{k}-1}\right\},\left\{\mathrm{x}_{\mathrm{k}}\right\}, \ldots,\left\{\mathrm{x}_{\mathrm{p}}\right\}\right\}$ is a partition of $\mathrm{X}$ into $\mathrm{X}$-independent sets and $\chi_{\mathrm{X}}(\mathrm{G})<\mathrm{p}$, a contradiction. Therefore, every vertex is of $\mathrm{X}$-degree $(\mathrm{p}-1)$. Hence, every vertex in $\mathrm{X}$ is ( $\mathrm{p}-1) \mathrm{X}$-regular.

Theorem 2.6: Let $\mathrm{G}$ be a bipartite graph on $|\mathrm{X}|=\mathrm{p}$ vertices.

Then $\frac{p}{\beta_{X}} \leq \chi_{X}(G) \leq p-\beta_{X}+1$. 
Proof: Let $\left\{\mathrm{X}_{1}, \mathrm{X}_{2}, \ldots, \mathrm{X}_{\chi \mathrm{X}}\right\}$ be a $\mathrm{X}$-chromatic partition of $\mathrm{X}(\mathrm{G})$. Then, $\quad\left|X_{i}\right| \leq \beta_{X}(G)$. Therefore, $p=\sum_{i=1}^{\chi_{X}}\left|X_{i}\right| \leq \chi_{X}(G) \beta_{X}(G)$.

Hence,

$\frac{p}{\beta_{X}} \leq \chi_{X}(G)$. Let $\mathrm{D}$ be a $\beta_{X}$-set of $\mathrm{G}$. Let $\mathrm{D}=\left\{\mathrm{x}_{1}, \mathrm{x}_{2}, \ldots, \mathrm{x}_{\beta \mathrm{X}}\right\}$. Then, $\Pi=\left\{D,\left\{x_{\beta X+1}\right\}, \ldots,\left\{x_{p}\right\}\right\}$ is a X-chromatic partition of G. Therefore, $\chi_{X}(G) \leq p-\beta_{X}+1$.

Hence, $\frac{p}{\beta_{X}} \leq \chi_{X}(G) \leq p-\beta_{X}+1$.

Theorem 2.7: Let $G$ be a connected bipartite graph, $\chi(G)=\chi_{X}(G)$ if and only if $\mathrm{G}$ is $\mathrm{G}_{1}, \mathrm{P}_{\mathrm{n}}, \mathrm{C}_{2 \mathrm{n}}, \mathrm{n} \neq 3$, where $\mathrm{G}_{1}$ is the graph $\mathrm{G}_{1}=\left(\mathrm{X}_{1} \cup \mathrm{X}_{2}, \mathrm{Y}, \mathrm{E}\right)$, vertices in $\mathrm{X}_{\mathrm{i}} \mathrm{i}=1,2$ are not $\mathrm{X}$-adjacent. At least one vertex in $\mathrm{X}_{1}$ is $\mathrm{X}$-adjacent to vertices of $\mathrm{X}_{2}$ through different $\mathrm{y}$ in $\mathrm{Y}$.

Proof: If $\mathrm{G}$ is $\mathrm{G}_{1}, \mathrm{P}_{\mathrm{n}}, \mathrm{C}_{2 \mathrm{n}}, \mathrm{n} \neq 3$, then $\chi(G)=\chi_{X}(G)$

Let $\chi(G)=\chi_{X}(G)$. Let $\mathrm{X}_{1}, \mathrm{X}_{2}$ be partition of $\mathrm{X}$ into $\mathrm{X}$ independent sets. The $\mathrm{X}$-neighbours of $\mathrm{X}_{1}$ are in $\mathrm{X}_{2}$ and vice versa. Since, $\mathrm{G}$ is connected, there is a vertex in one partition $\mathrm{X}$-adjacent to all the vertices in other partition, we get $\mathrm{G}_{1}$ or two vertices in $X_{1}$ has same $X$-neighbour in $X_{2}$ which gives $P_{n}, C_{2 n}$, $\mathrm{n} \neq 3$.

\section{HYPER COLOURING IN GRAPHS}

In this section, we define hyper independent colouring in graphs as given in [2] and find its bounds.

Definition 3.1: [4]A subset $S$ of $X$ is hyper independent set if there does not exist a vertex $y$ in $Y$ such that $\mathrm{N}(\mathrm{y})$ is contained in S.

Definition 3.2: [4]A hyper colouring of a graph is a partition of $\mathrm{X}$ into hyper independent sets, the hyper independent chromatic number $\chi_{h}(G)$, is the smallest order of a hyper independent colouring of $\mathrm{G}$.

Theorem 3.3: Given two positive integers, $k$ and $p$ such that $2 \leq k \leq p$, then there exists a graph $\mathrm{G}$ with $\chi_{h}(G)=k ;|Y|=k-2$ and $|X|=p$.

Proof: Let $X=\left\{x_{1}, x_{2}, \ldots, x_{p}\right\}$ be vertices of $X$. Let the vertices $\mathrm{x}_{1}, \mathrm{x}_{2}, \ldots, \mathrm{x}_{\mathrm{p}-\mathrm{k}+2}$ be adjacent to $\mathrm{y}_{1}$ in $\mathrm{Y}$. Let $\mathrm{x}_{\mathrm{i}}$ be $\mathrm{X}$ - adjacent to all other vertices of $\mathrm{X}$ through different $\mathrm{y}$ in $\mathrm{Y}(\mathrm{i}=\mathrm{p}$ $\mathrm{k}+3$ to $\mathrm{p}$ ). Then $(\mathrm{k}-2)$ vertices in $\mathrm{X}$ is of $\mathrm{X}$-degree $(\mathrm{p}-1)$ and $(\mathrm{p}$ $k+2)$ are $X$-adjacent through same $y$ in $Y$. Since each of the $(k-$ 2) vertices with $X$-degree (p-1) are $X$-adjacent through different vertices of $Y$, no two of them can be in a hyper independent set. Also $\mathrm{x}_{1}, \mathrm{x}_{2}, \ldots, \mathrm{x}_{\mathrm{p}-\mathrm{k}+2}$ cannot be all in the same hyper independent set. Therefore, there are at least two hyper independent set from $\mathrm{x}_{1}, \mathrm{x}_{2}, \ldots, \mathrm{x}_{\mathrm{p}-\mathrm{k}+2}$ and (k-2) hyper independent sets from $\mathrm{x}_{\mathrm{p}-\mathrm{k}+3}, \mathrm{x}_{\mathrm{p}-}$ ${ }_{\mathrm{k}+4}, \ldots, \mathrm{x}_{\mathrm{p}}$. Therefore, $\chi_{h}(G) \geq k$.

Consider

$\Pi=\left\{\left\{x_{1}, x_{2}, \ldots, x_{p-k+1}\right\},\left\{x_{p-k+2}\right\}, \ldots,\left\{x_{p}\right\}\right\}$. Then

$\Pi$ is a partition of $\mathrm{X}$ into $\mathrm{k}$ hyper independent sets. Therefore, $\chi_{h}(G) \leq k$. Hence, $\chi_{h}(G)=k$.

Definition 3.4: [4] A subset D of $\mathrm{X}$ is a $\mathrm{Y}$-dominating set if every $\mathrm{y}$ in $\mathrm{Y}$ is adjacent to at least one vertex in $\mathrm{D}$. The minimum cardinalilty of a Y-dominating set is called $\mathrm{Y}$ domination number and is denoted by $\gamma_{\mathrm{Y}}(\mathrm{G})$.

Theorem 3.5: [6] Let $G$ be a bipartite graph. A subset $D$ of $X$ is Y-dominating set if and only if X-D is hyper independent set.

Theorem 3.6: Let $G$ be a bipartite graph on $|X|=p$ vertices.

Then, $\frac{p}{p-\gamma_{Y}} \leq \chi_{h} \leq \gamma_{Y}+1$.

Proof: Let $\mathrm{S}$ be a minimum Y-dominating set of G. Then, (X-S) is a hyper independent set. Therefore, $\left\{\mathrm{X}-\mathrm{S},\left\{\mathrm{x}_{1}\right\},\left\{\mathrm{x}_{2}\right\}, \ldots,\left\{\mathrm{x}_{\mid \mathrm{S}}\right\}\right\}$ is a partition of $\mathrm{X}$ into hyper independent sets. Hence, $\chi_{h} \leq \gamma_{Y}+1$

Let $\Pi=\left\{\mathrm{X}_{1}, \mathrm{X}_{2}, \ldots, \mathrm{X}_{\mathrm{xh}}\right\}$ be a minimum hyper independent partition of $\mathrm{X}(\mathrm{G})$. Since, $\gamma_{Y}(G)+\beta_{h}(G)=p$, $\left|X_{i}\right| \leq \beta_{h}(G)=p-\gamma_{Y}(G) . \quad$ Therefore, $\left|X_{i}\right|=\sum_{i=1}^{\chi_{h}} X_{i} . \quad$ That is, $p \leq \chi_{h}(G)\left(p-\gamma_{Y}(G)\right)$. Therefore, $\frac{p}{p-\gamma_{Y}} \leq \chi_{h}$.

Theorem 3.7: Given two positive integers $a$ and $b$ with $2 \leq a \leq b$, there exists a graph $\mathrm{G}$ with $\chi_{h}(G)=a$, $|Y|=(b-a) a+\frac{(a-3)(a-2)}{2}+1$ and $\gamma_{Y}(G)=b-1$. 
Proof: Let $X=\left\{\mathrm{x}_{1}, \mathrm{x}_{2}, \ldots, \mathrm{x}_{\mathrm{b}-\mathrm{a}}, \mathrm{u}_{1}, \mathrm{u}_{2}, \ldots, \mathrm{u}_{\mathrm{a}-2}, \mathrm{w}_{11}, \mathrm{w}_{12}, \mathrm{w}_{21}, \mathrm{w}_{22}, \ldots, \mathrm{w}_{(\mathrm{b}-}\right.$ a) $\left.1, \mathrm{w}_{(\mathrm{b}-\mathrm{a}) 2}\right\}$. Let $\mathrm{x}_{1}, \mathrm{x}_{2}, \ldots, \mathrm{x}_{\mathrm{b}-\mathrm{a}}$, be $\mathrm{X}$-adjacent through same $\mathrm{y}$ in $\mathrm{Y}$. Let $\mathrm{u}_{\mathrm{i}}$ be $\mathrm{X}$-adjacent to $\mathrm{x}_{2}, \ldots, \mathrm{x}_{\mathrm{b}-\mathrm{a}}, \mathrm{u}_{1}, \mathrm{u}_{2}, \ldots, \mathrm{u}_{\mathrm{i}-1}$ through different $y$ in $Y(i=2$ to $a-2)$. Attach $P_{4}$ to every vertex $x_{i}(i=1$ to $\mathrm{b}-\mathrm{a})$ and let the vertices of this $\mathrm{P}_{4} \mathrm{X}$-adjacent to $\mathrm{x}_{\mathrm{i}}$ be $\mathrm{w}_{\mathrm{i} 1}, \mathrm{w}_{\mathrm{i} 2}$. Let $\mathrm{G}$ be the resulting graph. Clearly, $\chi_{h}(G) \geq a$.

$\Pi=\left\{\left\{\mathrm{x}_{1}, \mathrm{x}_{2}, \ldots, \mathrm{x}_{\mathrm{b}-\mathrm{a}-1}, \mathrm{w}_{12}, \mathrm{w}_{22}, \ldots, \mathrm{w}_{(\mathrm{b}-\mathrm{a}-1) 2}, \mathrm{w}_{(\mathrm{b}-2) 1}\right\}\right.$,

$\left.\left\{\mathrm{x}_{\mathrm{b}-\mathrm{a}}, \mathrm{w}_{(\mathrm{b}-\mathrm{a}) 2}, \mathrm{w}_{11}, \mathrm{w}_{21}, \ldots, \mathrm{w}_{(\mathrm{b}-\mathrm{a}-1) 1}\right\},\left\{\mathrm{u}_{1}\right\},\left\{\mathrm{u}_{2}\right\}, \ldots,\left\{\mathrm{u}_{\mathrm{a}-2}\right\}\right\} \quad$ is $\quad \mathrm{a}$ partition of $\mathrm{X}$ into hyper independent sets. Therefore, $\chi_{h}(G) \leq a$. Therefore, $\chi_{h}(G)=a$.

Clearly $\mathrm{S}=\left\{\mathrm{w}_{11}, \mathrm{w}_{21}, \ldots, \mathrm{w}_{(\mathrm{b}-\mathrm{a}) 1}, \mathrm{x}_{1}, \mathrm{u}_{1}, \mathrm{u}_{2}, \ldots, \mathrm{u}_{\mathrm{a}-2}\right\}$ is a $\mathrm{Y}$-dominating set with $\gamma_{Y}(G)=b-a+1+a-2=b-1$.

Example 3.8: Construction of graph with $\chi_{h}(G)=3$ and $\gamma_{Y}(G)=4$.

The partition $\left.\Pi=\left\{\mathrm{x}_{1}, \mathrm{w}_{12}, \mathrm{w}_{22}\right\},\left\{\mathrm{x}_{2}, \mathrm{w}_{11}, \mathrm{w}_{12}\right\},\left\{\mathrm{u}_{1}\right\}\right\}$ is a hyper independent set of $\mathrm{G}$ and $\mathrm{S}=\left\{\mathrm{w}_{11}, \mathrm{w}_{12}, \mathrm{x}_{1}, \mathrm{u}_{1}\right\}$ is a $\mathrm{Y}$-dominating set of G.

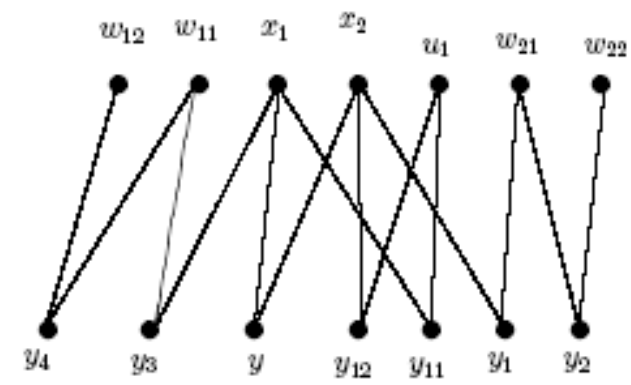

Observation 3.9: Every $X$-independent set is a hyper independent set. Therefore, every X-chromatic partition is a hyper independent chromatic partition of G. Therefore, $\chi_{h}(G) \leq \chi_{X}(G)$.

Theorem 3.10: Given positive integers $a>1$ and $b \geq a$, there exists a graph $\mathrm{G}$ with $\chi_{h}(G)=a$ and $\chi_{X}(G)=b$.

Proof: Let us assume $\mathrm{a}<\mathrm{b}$. Let $\mathrm{G}$ be a graph with bipartition $\mathrm{X}$ and $\mathrm{Y}$. Let $\mathrm{X}=\left\{\mathrm{x}_{1}, \mathrm{x}_{2}, \ldots, \mathrm{x}_{\mathrm{b}}\right\}$ and $\mathrm{Y}=\left\{\mathrm{y}_{1}, \mathrm{y}_{2}, \ldots, \mathrm{y}_{\mathrm{q}}\right\}$. Let the vertices $\mathrm{x}_{1}, \mathrm{x}_{2}, \ldots, \mathrm{x}_{\mathrm{b}}$ be $\mathrm{X}$-adjacent through same $\mathrm{y}$ in $\mathrm{Y}$. Therefore, $\chi_{X}(G)=b$, Let $\mathrm{x}_{\mathrm{i}}$ be X-adjacent to all $\mathrm{x}_{\mathrm{j}}, \mathrm{b}-\mathrm{a}+2$ $\leq \mathrm{i} \leq \mathrm{b} ; \mathrm{i} \neq \mathrm{j} ; \quad 1 \leq \mathrm{j} \leq \mathrm{b}$ through different $\mathrm{y}$ in $\mathrm{Y}$. Clearly, $\chi_{h}(G) \geq a$. Let $\Pi=\left\{\left\{\mathrm{x}_{1}, \mathrm{x}_{2}, \ldots, \mathrm{x}_{\mathrm{b}-\mathrm{a}+1}\right\}, \quad\left\{\mathrm{x}_{\mathrm{b}-}\right.\right.$ $\left.\left.{ }_{\mathrm{a}+2}\right\}, \ldots,\left\{\mathrm{x}_{\mathrm{b}}\right\}\right\}$. Then, $\Pi$ is a partition of $\mathrm{X}$ into hyper independent set of G. Therefore, $\chi_{h}(G) \leq a$.

Let $\mathrm{a}=\mathrm{b}$. Let $\mathrm{X}=\left\{\mathrm{x}_{1}, \mathrm{x}_{2}, \ldots, \mathrm{x}_{\mathrm{b}}\right\}$. Make every vertex in $\mathrm{X}$, (b-1) $\mathrm{X}$ regular through different $\mathrm{y}$ in $\mathrm{Y}$. Therefore, $\chi_{h}(G)=a$ and $\chi_{X}(G)=b$.

\section{X-DOMINATOR COLOURING OF A BIPARTITE GRAPH}

Domination and colouring have nice interactions in graphs. Partitioning the vertex set of a graph into subsets with desired property is an interesting problem. Colouring problem is also a partition problem. We initiate the study of X-dominator Xcolouring of graphs.

Definition 4.1: [1] A dominator colouring of $G$ is defined to be a proper colouring in which every vertex dominates a colour class. The dominator chromatic number, $\chi_{d}(G)$ is the minimum number of colours that allows a dominator colouring of G.

Definition 4.2: [4] A subset $\mathrm{S}$ of $\mathrm{X}$ is an $\mathrm{X}$-dominating set if every vertex in $\mathrm{X}$-D is $\mathrm{X}$-adjacent to at least one vertex in $\mathrm{D}$. A $\mathrm{X}$-dominating set $\mathrm{S}$ is a minimal $\mathrm{X}$-dominating set if no proper subset of $\mathrm{S}$ is $\mathrm{X}$-dominating set. The minimum cardinality of a minimal $\mathrm{X}$-dominating set is called the $\mathrm{X}$-domination number of $\mathrm{G}$ and is denoted by $\gamma_{X}(G)$.

Definition 4.3: Let $\mathrm{G}=(\mathrm{X}, \mathrm{Y}, \mathrm{E})$ be a graph. A $\mathrm{X}$-independent partition of $\mathrm{X}, \quad \Pi=\left(X_{1}, X_{2}, \ldots, X_{\chi}\right)$ is called $\mathrm{X}$ dominator $\mathrm{X}$-colouring of $\mathrm{G}$ if every vertex $\mathrm{x}$ in $\mathrm{X}, \mathrm{X}$-dominates some colour class in $\Pi$. We assume $\mathrm{x}$ in $\mathrm{X} X$-dominates $\{\mathrm{x}\}$. The smallest cardinality of $\mathrm{X}$-dominator $\mathrm{X}$-colouring of $\mathrm{G}$ is called $\mathrm{X}$-dominator, $\mathrm{X}$-colouring number of $\mathrm{G}$ and is denoted by $\chi_{X} d(G)$.

Example 4.4: For any bipartite graph $\mathrm{G}=(\mathrm{X}, \mathrm{Y}, \mathrm{E})$ with vertex $\mathrm{X}=\left\{\mathrm{x}_{1}, \mathrm{x}_{2}, \mathrm{x}_{3}, \ldots, \mathrm{x}_{\mathrm{p}}\right\}$ then $\left.\Pi=\left\{\mathrm{x}_{1}\right\},\left\{\mathrm{x}_{2}\right\}, \ldots,\left\{\mathrm{x}_{\mathrm{p}}\right\}\right\}$ is clearly a $\mathrm{X}$-dominator, $\mathrm{X}$-colouring of $\mathrm{G}$. Therefore, X-dominator $\mathrm{X}$ colouring of every graph exists.

$\operatorname{Remark}$ 4.5: $1 \leq \chi_{X} d(G) \leq \mathrm{p}$.

Remark 4.6: Since any $\mathrm{X}$-dominator, $\mathrm{X}$-colouring of $\mathrm{G}$ is a $\mathrm{X}$ colouring of G, we have $\chi_{X}(G) \leq \chi_{X} d(G)$. 
Theorem 4.7: Let $\mathrm{G}=(\mathrm{X}, \mathrm{Y}, \mathrm{E})$ be a bipartite graph with $|\mathrm{X}|=\mathrm{p}$, $|\mathrm{Y}|=\mathrm{q}$. Then, $\quad \chi_{X} d(G)=p$ if and only if there exists a vertex in $\mathrm{Y}$ of degree $p$ or $q \geq p-1$.

Proof: If there exists a vertex in $\mathrm{Y}$ of degree $\mathrm{p}$ then $\chi_{X} d(G)=p . \quad$ If $\quad q \geq p-1 \quad$ then $\sum_{y \in Y} d(y) \geq p(p-1)$. Every vertex in $\mathrm{X}$ is $\mathrm{X}$-adjacent to other vertices in X. Therefore, $\chi_{X} d(G)=p$.

Conversely, suppose $\chi_{X} d(G)=p$. Let every point $\mathrm{y}$ in $\mathrm{Y}$ be such that $\mathrm{d}(\mathrm{y})<\mathrm{p}$ and $\mathrm{q}<\mathrm{p}-1$. Let $\mathrm{x}_{1}, \mathrm{x}_{2}, \ldots, \mathrm{x}_{\mathrm{r}}$ be the vertices in $X$ which are adjacent to $y$ where $r=d(y)<p$. There exists $\mathrm{x}_{\mathrm{r}+1}$ which is not $\mathrm{X}$-adjacent to any $\mathrm{x}_{\mathrm{i}} 1 \leq \mathrm{i} \leq \mathrm{r}$ say $x_{r}$. Then $\left\{\left\{\mathrm{x}_{1}, \mathrm{x}_{2}, \ldots, \mathrm{x}_{\mathrm{r}-1}\right\},\left\{\mathrm{x}_{\mathrm{r}}, \mathrm{x}_{\mathrm{r}+1}\right\}, \ldots,\left\{\mathrm{x}_{\mathrm{p}}\right\}\right\}$ is a $\mathrm{X}$-dominator, $\mathrm{X}$-colouring of $\mathrm{G}$. A contradiction to $\chi_{X} d(G)=p$ Therefore, there exists a vertex in $\mathrm{Y}$ of degree $\mathrm{p}$ or $q \geq p-1$.

Theorem 4.8: Let $\mathrm{G}=(\mathrm{X}, \mathrm{Y}, \mathrm{E})$ be a bipartite graph with $|\mathrm{X}|=\mathrm{p}$, $|\mathrm{Y}|=\mathrm{q}$. Then $\chi_{X} d(G)=1$ if and only if $G \cong p K_{1, a}$.

Proof: If $G \cong p K_{1, a}$ then $\chi_{X} d(G)=1$.

Conversely, if $\chi_{X} d(G)=1$ then every vertex in X are Xindependent. Therefore, $G \cong p K_{1, a}$.

Theorem 4.9: Let $\mathrm{G}$ be a connected bipartite graph. Then $\max \left\{\chi_{X}(G), \gamma_{X}(G)\right\} \leq \chi_{X} d(G) \leq$ $\chi_{X}(G)+\gamma_{X}(G)$.

Proof: A X-dominatorX-colouring must be a proper Xcolouring, whe have $\chi_{X}(G) \leq \chi_{X} d(G)$. Also, let $\mathrm{C}$ be a minimum $\mathrm{X}$-dominator, $\mathrm{X}$-colouring of $\mathrm{G}$. For each colour class of $\mathrm{X}$, let $\mathrm{x}_{\mathrm{i}}$ be a vertex in the class $\mathrm{I}$, with $1 \leq i \leq \chi_{X} d(G)$. Let $S=\left\{x_{i}: 1 \leq i \leq \chi_{X} d(G)\right\}$. Let $\mathrm{v}$ belong to $\mathrm{X}(\mathrm{G})$. Then $\mathrm{v}$ X-dominates a colour class i, for some i ( $1 \leq i \leq \chi_{X} d(G)$.) Then $\mathrm{v}$ is $\mathrm{X}$-dominated by the colour class i, in particular $\mathrm{x}_{\mathrm{i}}$. Therefore, $\gamma_{X}(G) \leq|S|=\chi_{X} d(G)$. Hence,
Let $\mathrm{C}$ be a proper $\mathrm{X}$-colouring of $\mathrm{X}$ with $\chi_{X}(G)$ colours. Assign colours $\quad \chi_{X}(G)+1, \quad \chi_{X}(G)+2, \ldots$, $\chi_{X}(G)+\gamma_{X}(G)$ to the vertices of a minimum $\mathrm{X}$ dominating set of $\mathrm{G}$ leaving the rest of the vertices coloured as before. This is a X-dominator, $\mathrm{X}$-colouring of $\mathrm{G}$, since it is still a proper $\mathrm{X}$-colouring and the $\mathrm{X}$-dominating set provides the colour class that every vertex $\mathrm{X}$-dominates.

Theorem 4.10: Given positive integers a, b, c such that $c \geq 2(b-a)+1$, there exists a graph $\mathrm{G}$ such that $\chi_{X}(G)=a ; \chi_{X} d(G)=b$ and $|Y|=c$.

Proof: Let $\mathrm{G}=(\mathrm{X}, \mathrm{Y}, \mathrm{E})$ be the graph. Let $\mathrm{X}=\left\{\mathrm{x}_{11}, \mathrm{x}_{12}\right.$, $\left.\ldots, \mathrm{X}_{1 \mathrm{a}}, \mathrm{X}_{21}, \mathrm{X}_{22}, \ldots, \mathrm{X}_{2 \mathrm{a}}, \ldots, \mathrm{X}_{(\mathrm{b}-\mathrm{a}+1) 1}, \ldots, \mathrm{X}_{(\mathrm{b}-\mathrm{a}+1) \mathrm{a}}\right\}$. $\mathrm{Y}=\left\{\mathrm{y}_{1}, \mathrm{y}_{12}, \mathrm{y}_{2}, \ldots, \mathrm{y}_{(\mathrm{b}-\mathrm{a})(\mathrm{b}-\mathrm{a}+1)}, \mathrm{y}_{\mathrm{b}-\mathrm{a}+1}\right\} . \quad$ The edges $\mathrm{E}(\mathrm{G})=\left\{\mathrm{x}_{11} \mathrm{y}_{1}, \mathrm{x}_{12} \mathrm{y}_{1}, \ldots, \mathrm{x}_{1 \mathrm{a}} \mathrm{y}_{1}, \mathrm{x}_{1 \mathrm{a}} \mathrm{y}_{12}, \ldots, \mathrm{x}_{(\mathrm{b}-\mathrm{a}+1) \mathrm{a}} \mathrm{y}_{\mathrm{b}-\mathrm{a}+1}\right\} . \quad$ Then, $\left\{\left\{\mathrm{x}_{11}, \mathrm{x}_{21}, \ldots, \mathrm{x}_{(\mathrm{b}-\mathrm{a}+1)}\right\},\left\{\mathrm{x}_{12}, \mathrm{x}_{22}, \ldots, \mathrm{x}_{(\mathrm{b}-\mathrm{a}+1) 2}, \ldots,\left\{\mathrm{x}_{1 \mathrm{a}}, \ldots, \mathrm{x}_{(\mathrm{b}-\mathrm{a}+1) \mathrm{a}}\right\}\right\}\right.$ is a minimum partition of $\mathrm{X}$ into $\mathrm{X}$-independent sets. Therefore, $\chi_{X}(G)=a$.

The partition $\left\{\left\{\mathrm{x}_{11}, \mathrm{x}_{21}, \ldots, \mathrm{x}_{(\mathrm{b}-\mathrm{a}+1)}\right\}, \quad \ldots, \quad\left\{\mathrm{x}_{\mathrm{i} 1}\right\},\left\{\mathrm{x}_{\mathrm{i} 2}\right\}, \ldots\right.$ $\left.\left\{\mathrm{x}_{\mathrm{ia}}\right\}, \ldots,\left\{\mathrm{x}_{1 \mathrm{a}}, \ldots, \mathrm{x}_{(\mathrm{b}-\mathrm{a}+1) \mathrm{a}}\right\}\right\}$ is a minimum $\mathrm{X}$-dominator, $\mathrm{X}$ colouring of G. $\chi_{X} d(G)=a-1+b-a+1=b$ and $|Y|=b-a+1+b-a=2(b-a)+1 . \quad$ Therefore, $c \geq 2(b-a)+1$.

Theorem 4.11: Given a positive integer $\mathrm{k}$, there exists a graph with $\chi_{X} d(G)-\chi_{h}(G)=k$.

Proof: Let the vertices of $X$ be $\left\{x_{11}, x_{12}, x_{13}, \ldots, x_{(k-1) 1}, x_{(k-1) 2}, x_{(k-1) 3}, x_{(k-1) 4}\right\} . \quad \mathrm{x}_{\mathrm{i1}}$, $\mathrm{x}_{\mathrm{i} 2}, \mathrm{x}_{\mathrm{i} 3}, \mathrm{x}_{\mathrm{i} 4}$ are adjacent to $\mathrm{y}_{\mathrm{i}} \mathrm{i}=1$ to $\mathrm{k}-1 . \mathrm{x}_{\mathrm{i} 4}$ and $\mathrm{x}_{(\mathrm{i}+1) 1}$ are adjacent to $\mathrm{y}_{\mathrm{i}(\mathrm{i}+1)} \mathrm{i}=1$ to $\mathrm{k}-2$.

$\Pi=\left\{\left\{\mathrm{x}_{11}, \mathrm{x}_{12}, \ldots, \mathrm{x}_{(\mathrm{k}-1) 3}\right\},\left\{\mathrm{x}_{14}, \mathrm{x}_{24}, \ldots, \mathrm{x}_{(\mathrm{k}-1) 4}\right\}\right\}$ is a partition of $\mathrm{X}$ into hyper independent sets. Therefore, $\chi_{h}(G)=2$.

$\Pi=\left\{\left\{\mathrm{x}_{11}, \mathrm{x}_{21}, \ldots, \mathrm{x}_{(\mathrm{k}-1) 1}\right\}, \quad\left\{\mathrm{x}_{12}, \mathrm{x}_{22}, \ldots, \mathrm{x}_{(\mathrm{k}-1) 2}, \mathrm{x}_{13}, \mathrm{x}_{23}, \ldots, \quad \mathrm{x}_{(\mathrm{k}-}\right.\right.$ $\left.\left.{ }_{1) 3}\right\},\left\{\mathrm{x}_{14}\right\}, \ldots,\left\{\mathrm{x}_{(\mathrm{k}-1) 4}\right\}\right\}$ is a partition of $\mathrm{X}$ into $\mathrm{X}$-dominator $\mathrm{X}$ colouring of $\mathrm{G}$. Therefore, $\chi_{X} d(G)=k+2$. Hence, $\chi_{X} d(G)-\chi_{h}(G)=k$.

$\max \left\{\chi_{X}(G), \gamma_{X}(G)\right\} \leq \chi_{X} d(G)$. 


\section{BIPARTITE THEORY DOMINATOR COLOURING}

The Bipartite graph $\mathrm{VE}(\mathrm{G})$ constructed from an arbitrary graph $\mathrm{G}=(\mathrm{V}, \mathrm{E})$ is defined as in $[2] . \mathrm{VE}(\mathrm{G})=(\mathrm{V}, \mathrm{E}, \mathrm{F})$ is defined by the edges $\mathrm{F}=\{(\mathrm{u}, \mathrm{e}): \mathrm{e}=(\mathrm{u}, \mathrm{v})$ in $\mathrm{E}\}$. $\mathrm{VE}(\mathrm{G}) \cong \mathrm{S}(\mathrm{G})$, where $\mathrm{S}(\mathrm{G})$ denotes the subdivision graph of $\mathrm{G}$.

Theorem 5.1: For any graph G, $\chi_{X} d(V E(G))=\chi_{d}(G)$.

Proof: Let $\chi_{X} d(V E(G))=k$. There exists a partition of $\mathrm{X}, \Pi=\left\{\mathrm{X}_{1}, \mathrm{X}_{2}, \ldots, \mathrm{X}_{\mathrm{k}}\right\}$ of $\mathrm{X}$-independent sets such that every vertex $x$ in $X X$-dominates some colour class in $\Pi$. In $G$, $\Pi^{1}=\left\{\mathrm{X}_{1}, \mathrm{X}_{2}, \ldots, \mathrm{X}_{\mathrm{k}}\right\}$ is a partition of $\mathrm{V}$ into independent sets such that every $\mathrm{v}$ in $\mathrm{V}$ dominates some colour class in $\Pi^{1}$. Therefore, $\Pi^{1}$ is a dominator colouring of $\mathrm{G}$. Hence, $\chi_{d}(G) \leq k=\chi_{X} d(\operatorname{VE}(G))$.

Conversely, let $\chi_{d}(G)=r$. Let $\Pi=\left\{\mathrm{V}_{1}, \mathrm{~V}_{2}, \ldots, \mathrm{V}_{\mathrm{k}}\right\}$ is a partition of $\mathrm{V}$ into independent sets such that every vertex $\mathrm{V}$ in $\mathrm{V}$ dominates some colour class in $\Pi$. In $\operatorname{VE}(G)$, $\Pi^{1}=\left\{\mathrm{V}_{1}, \mathrm{~V}_{2}, \ldots, \mathrm{V}_{\mathrm{k}}\right\}$ is a partition of $\mathrm{X}$ in to $\mathrm{X}$-independent sets and every $\mathrm{x}$ in $\mathrm{X} X$-dominates some colour class in $\Pi^{1}$. Therefore, $\Pi^{1}$ is a X-dominator, X-colouring of $\operatorname{VE}(G)$. Hence, $\quad \chi_{X} d(\operatorname{VE}(G)) \leq r=\chi_{d}(G) . \quad$ Therefore, $\chi_{X} d(V E(G))=\chi_{d}(G)$.

The graph $E V(G)=(E, V, K)$ is defined by edges $K=\{(e, u): e=u v$ in $\mathrm{E}$ \}.

Theorem 5.2: $\quad$ For $\quad$ any $\quad$ graph $\quad \mathrm{G}$,
$\chi_{X} d(E V(G))=\chi_{d}^{1}(G)$

Proof: Let $\chi_{X} d(E V(G))=k$. There exists a partition of $\mathrm{X}, \Pi=\left\{\mathrm{X}_{1}, \mathrm{X}_{2}, \ldots, \mathrm{X}_{\mathrm{k}}\right\}$ of $\mathrm{X}$-independent sets such that every vertex $\mathrm{x}$ in $\mathrm{X}, \mathrm{X}$-dominates some colour class in $\Pi$. In $\mathrm{G}$, $\Pi^{1}=\left\{\mathrm{X}_{1}, \mathrm{X}_{2}, \ldots, \mathrm{X}_{\mathrm{k}}\right\}$ is a partition of $\mathrm{E}$ into independent sets such that every e in $\mathrm{E}$ dominates some colour class in $\Pi^{1}$. Therefore, $\Pi^{1}$ is an edge dominator colouring of G. Hence, $\chi_{d}(G) \leq k=\chi_{X} d(E V(G))$.

Conversely, let $\chi_{d}{ }^{1}(G)=r$. Let $\Pi=\left\{\mathrm{E}_{1}, \mathrm{E}_{2}, \ldots, \mathrm{E}_{\mathrm{k}}\right\}$ is a partition of $E$ into independent sets such that every edge e in $E$ dominates some colour class in $\Pi$. In $\operatorname{EV}(G)$, $\Pi^{1}=\left\{\mathrm{E}_{1}, \mathrm{E}_{2}, \ldots, \mathrm{E}_{\mathrm{k}}\right\}$ is a partition of $\mathrm{X}$ in to $\mathrm{X}$-independent sets and every $\mathrm{x}$ in $\mathrm{X} \mathrm{X}$-dominates some colour class in $\Pi^{1}$. Therefore, $\Pi^{1}$ is a X-dominator, X-colouring of $\operatorname{EV}(\mathrm{G})$. Hence, $\quad \chi_{X} d(E V(G)) \leq r=\chi_{d}^{1}(G) . \quad$ Therefore, $\chi_{X} d(E V(G))=\chi^{1}{ }_{d}(G)$.

Let $\mathrm{V}^{1}$ be a copy of the vertices $\mathrm{V}$ of $\mathrm{G}$. (a) The graph $\mathrm{VV}(\mathrm{G})=\left(\mathrm{V}, \mathrm{V}^{1}, \mathrm{E}^{1}\right)$ is defined by the edges $\mathrm{E}^{1}=\left\{\left(\mathrm{u}, \mathrm{v}^{1}\right):(\mathrm{u}, \mathrm{v})\right.$ in $\left.\mathrm{E}\right\}$.

From a graph $\mathrm{G}=(\mathrm{V}, \mathrm{E})$ the graph $\mathrm{G} 2$ and $\mathrm{G}^{2}$ can be constructed as follows: $\mathrm{G} 2$ and $\mathrm{G}^{2}$ have the same vertex set as $\mathrm{G}$, with two vertices $\mathrm{u}$ and $\mathrm{v}$ adjacent to G2 if and only if they have a common neighbor in $\mathrm{G}$, and adjacent in $\mathrm{G}^{2}$ if and only if $\mathrm{d}(\mathrm{u}, \mathrm{v}) \leq 2$ in $\mathrm{G}$.

Theorem 5.3: $\quad$ For any graph $\mathrm{G}$,
$\chi_{X} d(V V(G))=\chi_{d}(G 2)$

Proof: Let $\chi_{X} d(V V(G))=k$. There exists a partition of $\mathrm{X}, \Pi=\left\{\mathrm{X}_{1}, \mathrm{X}_{2}, \ldots, \mathrm{X}_{\mathrm{k}}\right\}$ of $\mathrm{X}$-independent sets such that every vertex $\mathrm{x}$ in $\mathrm{X} \mathrm{X}$-dominates some colour class in $\Pi$. Any two vertices in the same partition are not $X$-adjacent. In G2, any two vertices in $X_{i}$ are not adjacent. $\Pi^{1}=\left\{X_{1}, X_{2}, \ldots, X_{k}\right\}$ is a partition of $\mathrm{V}(\mathrm{G} 2)$ into independent sets such that every $\mathrm{v}$ in V(G2) dominates some colour class in $\Pi^{1}$. Therefore, $\Pi^{1}$ is a dominator colouring of G2. Hence, $\chi_{d}(G 2) \leq k=\chi_{X} d(V V(G))$.

Conversely, let $\chi_{d}(G 2)=r$. Let $\Pi=\left\{\mathrm{V}_{1}, \mathrm{~V}_{2}, \ldots, \mathrm{V}_{\mathrm{k}}\right\}$ is a partition of $V(G 2)$ into independent sets such that every vertex $\mathrm{v}$ in $\mathrm{V}(\mathrm{G} 2)$ dominates some colour class in $\Pi$. In $\mathrm{G}$, any two vertices in the same partition do not have a common neighbor. In $\mathrm{VV}(\mathrm{G})$, any two vertices in $\mathrm{V}_{\mathrm{i}}, \mathrm{i}=1$ to $\mathrm{k}$ are not $\mathrm{X}$-adjacent. Hence, in $\mathrm{VV}(\mathrm{G}), \Pi^{1}=\left\{\mathrm{V}_{1}, \mathrm{~V}_{2}, \ldots, \mathrm{V}_{\mathrm{k}}\right\}$ is a partition of $\mathrm{X}$ in to $\mathrm{X}$-independent sets and every $\mathrm{x}$ in $\mathrm{X} \mathrm{X}$-dominates some colour class in $\Pi^{1}$. Therefore, $\Pi^{1}$ is a X-dominator, X-colouring of $\mathrm{VV}(\mathrm{G})$. Hence, $\quad \chi_{X} d(V V(G)) \leq r=\chi_{d}(G 2)$.

Therefore, $\chi_{X} d(V V(G))=\chi_{d}(G 2)$.

The graph $\mathrm{VV}^{+}(\mathrm{G})=\left(\mathrm{V}, \mathrm{V}^{1}, \mathrm{E}^{+}\right)$contains the edges $\mathrm{E}^{1}$ of the graph $\mathrm{VV}$ together with the edges $\left\{\left(\mathrm{u}, \mathrm{u}^{1}\right): \mathrm{u}\right.$ in $\left.\mathrm{V}\right\}$.

Theorem 5.4: $\quad$ For $\quad$ any $\quad$ graph $\quad \mathrm{G}$,
$\chi_{X} d\left(V V^{+}(G)\right)=\chi_{d}\left(G^{2}\right)$

Proof: Let $\chi_{X} d\left(V V^{+}(G)\right)=k$. There exists a partition of $X, \Pi=\left\{X_{1}, X_{2}, \ldots, X_{k}\right\}$ of $X$-independent sets such that 
every vertex $\mathrm{x}$ in $\mathrm{X}, \mathrm{X}$-dominates some colour class in $\Pi$. In $\mathrm{G}^{2}, \quad \Pi^{1}=\left\{\mathrm{X}_{1}, \mathrm{X}_{2}, \ldots, \mathrm{X}_{\mathrm{k}}\right\}$ is a partition of $\mathrm{V}\left(\mathrm{G}^{2}\right)$ into independent sets such that every $\mathrm{v}$ in $\mathrm{V}\left(\mathrm{G}^{2}\right)$ dominates some colour class in $\Pi^{1}$. Therefore, $\Pi^{1}$ is a dominator colouring of $\mathrm{G}^{2}$. Hence, $\chi_{d}\left(G^{2}\right) \leq k=\chi_{X} d\left(V V^{+}(G)\right)$.

Conversely, let $\chi_{d}\left(G^{2}\right)=r$. Let $\Pi=\left\{\mathrm{V}_{1}, \mathrm{~V}_{2}, \ldots, \mathrm{V}_{\mathrm{r}}\right\}$ is a partition of $\mathrm{V}\left(\mathrm{G}^{2}\right)$ into independent sets such that every vertex $\mathrm{v}$ in $\mathrm{V}\left(\mathrm{G}^{2}\right)$ dominates some colour class in $\Pi$. In $\mathrm{VV}^{+}(\mathrm{G})$, $\Pi^{1}=\left\{\mathrm{V}_{1}, \mathrm{~V}_{2}, \ldots, \mathrm{V}_{\mathrm{r}}\right\}$ is a partition of $\mathrm{X}$ in to $\mathrm{X}$-independent sets and every $\mathrm{x}$ in $\mathrm{X} X$-dominates some colour class in $\Pi^{1}$. Therefore, $\Pi^{1}$ is a X-dominator, $\mathrm{X}$-colouring of $\mathrm{VV}^{+}(\mathrm{G})$. Hence, $\quad \chi_{X} d\left(V V^{+}(G)\right) \leq r=\chi_{d}\left(G^{2}\right)$. Therefore, $\chi_{X} d\left(V V^{+}(G)\right)=\chi_{d}\left(G^{2}\right)$.

Corollary 5.5: For any graph G,

(i) $\operatorname{Max}\{\gamma(\mathrm{G}), \chi(\mathrm{G})\} \leq \chi_{\mathrm{d}}(\mathrm{G}) \leq \chi(\mathrm{G})+\gamma(\mathrm{G})$

(ii) $\operatorname{Max}\left\{\gamma^{1}(\mathrm{G}), \chi^{1}(\mathrm{G})\right\} \leq \chi_{\mathrm{d}}^{1}(\mathrm{G}) \leq \gamma^{1}(\mathrm{G})+\chi^{1}(\mathrm{G})$.

\section{CONCLUSION}

The bounds of X-chromatic number and hyper independent number are given. We introduce the bipartite theory of dominator colouring of a graph $\mathrm{G}$. Given any three positive integers $a, b$, c such that $c \geq 2(b-a)+1$, we have proved the existence of a bipartite graph $G$ such that $\chi_{X}(G)=a, \chi_{X} d(G)=b$ and $|\mathrm{Y}|=\mathrm{c}$.

\section{REFERENCES}

[1] Gera.R, Horton.S and Ramussen.C, Dominator coloring and safe clique partition, Congressus Numerantium, Volume 181 (2006), 19-32.

[2] Haynes T.W, Hedetneimi S.T, Slater P.J, Fundamentals of domination in graphs, Marcel Dekker., Inc., 1988.

[3] Haynes T.W, Hedetneimi S.T, Slater P.J, Domination in graphs Advanced topics, Marcel Dekker., Inc., 1988.

[4] Stephen Hedetneimi, Renu Laskar, A Bipartite theory of graphs I, Congressus Numerantium, Volume 55, December 1986, 5-14.

[5] Stephen Hedetneimi, Renu Laskar, A Bipartite theory of graphs II, Congressus Numerantium, Volume 64, November 1988, 137-146.

[6] Swaminathan.V, Venkatakrishnan Y.B, Some Characterization theorems, Mathematical and computational Models, edited by R.Nadarajan et al., Narosa Publishing House, India (2008) 201-206. 